\title{
GREEN SYNTHESIS OF ANTIBACTERIAL: A NOVEL NANOCOMPOSITE FROM POLYVINYL ALCOHOL/POLYANILINE/AG
}

\section{Neama Ahmed Sobhy Ahmed ${ }^{1}$ and Marwa Mahmoud El-Tayeb ${ }^{1}$}

\begin{abstract}
A new nancomposite based on polyvinyl alcohol/polyaniline/Ag (PVA/PA/Ag) has been synthesized. An eco-friendly chemical reduction method was used to produce Ag nanoparticle solution from $\mathrm{Ag}^{+}$ions. The polymerization of aniline occurred for the preparation of poly aniline (PA) in the presence of ammonium persulfate. With exposure to Ag nanoparticles on the PVA/PA composite, a new nanocomposite was obtained. The morphology of the new nanocomposite was studied by scanning electron microscopy (SEM), fourier transorm infrared (FT-IR) analysis, and x-ray diffraction (XRD). According to XRD analysis, the size of nanoparticles was found to be in the range of 15-20 nm. SEM images showed the shape of nanoparticles as triangle which is a benign shape for antibacterial analysis. The bacterial activity of the obtained nanocomposite was also evaluated against Gram negative Escerichia coli (E.coli) and Gram positive bacteria staphylococcus aureus (staph. Aureus) by the disc diffusion method. The antibacterial study showed that the PVA/PA/Ag composite had good antibacterial activity and PVA/PA/Ag nanocomposites were found to be effective against two bacteria.
\end{abstract}

Keywords: Nanocomposite; Polyvinyl Alcohol; Poly aniline; Ag nanoparticles; Antibacterial activity.

\section{INTRODUCTION}

$\mathrm{I}$ $\mathrm{n}$ recent years, noble metal nanoparticles have been the subjects of focused researchers due to their unique electronic, optical, mechanical, magnetic and chemical properties that are significantly different from those of bulk materials [1]. The preparation of colloidal AgNPs is of great interest for their unusual chemical and physical properties and their applications [2].

\footnotetext{
${ }^{1}$ Sanitary \& Environmental Engineering Institute, Housing \& Building National Research Center
} 
Silver nanoparticles (AgNPs) are well known for strong antibacterial properties and no harm to human cells [3]. The main advantage of AgNPs is that even molar concentrations are effective than micro molar concentration of silver ions [4]. In addition, AgNPs were found to be relatively non toxic to human cells [5]. There are various methods to prepare nanoparticles. The most important ones are follows: chemical reduction [6]. Optical reduction [7], hydrogel method [8], Sedimentation method [9], UV and gama irradiation [6] and biosynthesis method [10]. Among these methods, the chemical reduction process is the most common industrial method for Ag nanoparticle synthesis. This method has the highest production efficiency and ability for use in a wide range of nanoparticle and nanocomposite production methods [11].

Polymer blending technology is an effective way to obtain new polymeric materials with optimized properties. The advantages of this technology include versatility, simplicity, and inexpensiveness [12,13], numerous polymers have been employed to prepare polymer-silver nanocomposites and have been successfully used for the synthesis of metal nanoparticles $[14,15]$. Polymer stabilizes the metal nanoparticle-polymer composite, and hence, the nanoparticles attached to the polymer chains will disperse in the solution when the composite dissolve [16]. Therefore, the synthesis protocol often involve a stabilization process by reducing the silver ions in the presence of surfactant, polymers and hydrogels [14]. There are many studies for the synthesis of polymeric nanocomposites in the literature. For example, The polyacrilonitrile/montmorillonite/Ag nanicomposites were prepared using the chemical reduction of $\mathrm{Ag}^{+}$(in situ) [17]. The antibacterial activities of the silver nanoparticle solution, which was obtained by soaking the polyacrilonitrile/montmorillonite/Ag nanocomposite films in distilled water, were tested using the paper disc diffusion method. The results showed that the silver nanoparticle solution was quite effective against tiny bacteria such as Staphylococcus aureus, Escerichia coli and klebsiella pneumonia.

Polyvinyl alcohol (PVA) have several advantages, such as high biodegradability, biocompatibility, hydrophilicity and ability to form fiber. So that, PVA has a lot of medical applications and is used by virtue of elasticity and tensile strength in some polymers like chitosan. It can be 
used for coating of cellulose [18], Titanium dioxide [19]. polyaniline (PA) is another polymer which also used for coating of $\mathrm{Ag}[20,21]$, zeolite [22], silica ge [23], and nanofibers, especially gelatin nano fibers [24,25].

The present study reported a facile synthesis of nanocomposite based on Ag nanoparticles coated by Poly Vinyl Alcohol and Poly Aniline polymers. Ag nanoparticles are prepared using chemical reduction method, a simple, low cost and facile method. The developed nanocomposite was evaluated for their antibacterial applications against two pathogenic bacteria, including saph. Aureus (Gram positive) and E.coli (Gram negative) by using disk diffusion method.

\section{MATERIALS AND METHODS}

\subsection{Materials}

All chemicals were of analytical reagent grade and used without further purification. All chemicals were purchased from Merck (Mumbai, India). Silver nitrate (AgNO3) was used as $\mathrm{Ag}+$ source and aniline in aniline hydrochloride form was used as monomer for polyaniline (PA) synthesis.

\subsection{Ag nanoparticles preparation}

Ag nanoparticles were synthesized by the chemical reduction of $\mathrm{AgNO}_{3}$ using $\mathrm{NaBH}_{4}$ (1:3) in deionized water according to procedure described by [26]. Silver nitrate solution was prepared with different concentrations $(0.005,0.008,0.01$ and 0.012$)$ in DI water. The aqueous solution of $\mathrm{NaBH}_{4}$ was maintained at $5^{\circ} \mathrm{C}$ for 20 min. and was titrated using $\mathrm{AgNO}_{3}$ solution $(200 \mathrm{ml})$ under constant stirring. The reduction reaction was continued for $40 \mathrm{~min}$. at room temperature. Then, the yellowish-red colloid of Ag nanoparticle solution was obtained.

\subsection{Aniline hydrochloride preparation}

Aniline hydrochloride was synthesized [27] as follows: aniline and hydrochloric acid was mixed in the ratio 1:2. A $20 \mathrm{ml}$ of aniline was heated and $40 \mathrm{ml}$ of hydrochloric acid was added drop wise, the mixture was stirred by magnetic stirrer, the color changed from colorless to violet. Then, the solution was filtered and washed using concentrated hydrochloric acid. Then, the sediment was dried at $60^{\circ} \mathrm{C}$ in an oven. 


\subsection{PVA/PA/Ag nanocomposites}

The PVA/PA/Ag nanocomposites were synthesized by chemical oxidation polymerization of aniline in presence of PVA and Ag nanoparticle solution. Aniline-hydrochloride was added to the prepared Ag nanoparticles colloidal solution $(250 \mathrm{ml})$. The mixture was stirred for 15 min. and the PVA aqueous solution (dissolves with $0.1 \mathrm{MHCl}$ ) was added and the mixture was stirred for $30 \mathrm{~min}$. Then adding aqueous solution of ammonium persulfate, $(\mathrm{NH} 4)_{2} \mathrm{~S}_{2} \mathrm{O}_{8}$, the mixture was allowed to react for $10 \mathrm{~h}$ under constant stirring at $-3^{\circ} \mathrm{C}$.

\subsection{Micro organisms}

The antibacterial activity of prepared nanocomposites determined using two bacterial strains, E.coli and staph. Aureus.

\subsection{Characterization}

\subsubsection{FT-IR spectroscopy}

The nanocomposite formed were analyzed by fourier transform infrared (FT-IR) spectroscopy (Jasco FTIR-4100, Jasco, Japan) using KBr disks.

\subsection{2 $U V$-vis spectroscopy}

The absorption spectrum of mixtures was recorded at room temperature using UV-vis spectrophotometer (Shimadzu 3600, NIR UV, Kyoto, Japan) at a resolution of $1 \mathrm{~nm}$.

\subsubsection{X-ray diffraction (XRD)}

$\mathrm{X}$-ray diffraction (XRD) analysis of the products was measured using (X Pert Pro, Panalytical, Holland) at room temperature, using Nickel filtered $\mathrm{Cu} \mathrm{k} \alpha$ radiation generated at $45 \mathrm{kV}$, and $50 \mathrm{~mA}$. The diffraction patterns were determined over a diffraction angle range of $2 \theta=5^{\circ}-80^{\circ}$.

\subsubsection{Scanning electron microscopy (SEM)}

SEM was applied to observe the surface morphology of PVA/PA/Ag nanocomposite materials using (Inspect S, FEI Ltd., Holland) after gold coating.

\subsection{Antibacterial activity study}

The antibacterial PVA/PA/Ag nanocomposites was tested against E.coli and Staph. Aureus microorganisms by paper disk diffusion method according to procedure described by [17].

The Muller Hinton agar (MHA) powder was used as a culture medium for bacterial growth. $20 \mathrm{~g}$. of agar was dissolved in $500 \mathrm{ml}$ of distilled water, 
the clear brown solvent was obtained by boiling the solution. The MHA medium $(15 \mathrm{ml})$ as sterilized at $120^{\circ} \mathrm{C}$ for $60 \mathrm{~min}$. in autoclave, cooled to room temperature, and poured into sterilized petrie dishes $(10 \mathrm{~mm} \mathrm{X}$ $90 \mathrm{~mm}$ ), the petrie dishes are cooled over 24 hours. Filter paper disks according to the number of samples were placed on the surface of the medium and $40 \mathrm{ml}$ of each concentration of PVA/PA/Ag samples were dropped over disks by sampler to investigate antibacterial activity. The size of the zone of inhibition measures the effectiveness of the compounds, a more effective compound produces a larger clear area around the filter disk. All petrie dishes contained bacteria and antibacterial regents were incubated and maintained at $37^{\circ} \mathrm{C}$ for 24 hours. After this period, the diameters of the inhibition zones formed around each disk were determined and presented in $\mathrm{mm}$. The results concerning antibacterial activity (inhibition zone $<5 \mathrm{~mm}$ ), weak activity $(5 \mathrm{~mm})$, moderate activity $(6-12 \mathrm{~mm})$ and strong activity $(>13 \mathrm{~mm})$.

\section{RESULTS AND DISCUSSION}

In this study, nanoparticle colloidal solution was synthesized using reducing agent and ions to $\mathrm{Ag}$ nanoparticles by $\mathrm{NaBH}_{4}$ is as follows [28]. $\mathrm{NaBH}_{4}+\mathrm{AgNO}_{3} \rightarrow \mathrm{Ag}+1 / 2 \mathrm{H}_{2}+\mathrm{NaNO}_{3}+1 / 2 \mathrm{~B}_{2} \mathrm{H}_{6}$ To improve polymer properties is to combine the desired polymer with other polymers that have better properties. The combination of two or more polymers is an efficient method to synthesize new compounds with benign properties and many applications [11]. The polymer which have better properties can enhance the properties of a weak polymer. However, PA have advantages but has low solubility in common solvents. To overcome this problem, dispersing PA in soluble polymeric matrix like polyvinyl alcohol (PVA), poly ethylene oxide, poly styrene sulphonic acid and hydroxyl methyl cellulose. PVA improved the solubility of PA and the composite can be applied for Ag nanoparticle formation.

The PA/PVA/Ag nano composite was synthesized by polymerization of aniline hydrochloride in Ag nanoparticle colloid.

\subsection{FT-IR Spectroscopy}

Fig. 1 shows FT-IR spectra of synthesized nanocomposites. The free $\mathrm{OH}$ functional group has a broad peak at $3600-3650 \mathrm{~cm}^{-1}$, and the peak goes 
to $3200-3400 \mathrm{~cm}^{-1}$, the presence of $\mathrm{C}-\mathrm{H}$ and $\mathrm{CH}_{2}$ bonds in alkanes which are in the PVA structure was confirmed with the intense bending peaks around $2900-3000 \mathrm{~cm}^{-1}$ and $1465 \mathrm{~cm}^{-1}$ and an intense peak in $1000-3000 \mathrm{~cm}^{-1}$ shows the existence of the $\mathrm{C}-\mathrm{N}$ bond in polyaniline chains.

The presence of benzene in the polyaniline structure was confirmed with an intense tensile peak around $1500-1600 \mathrm{~cm}^{-1}$.

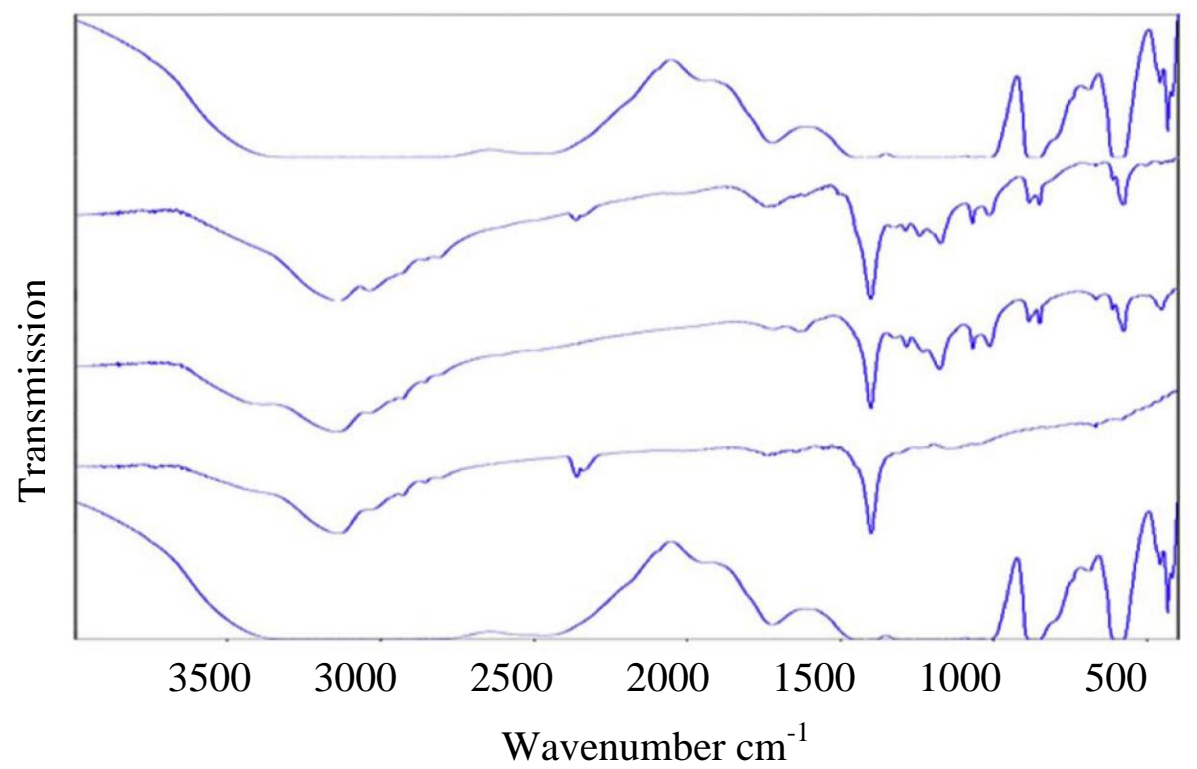

Figure (1) FT-IR spectra of prepared nanocomposites at different concentrations of silver nanoparticles; $10 \%$ (A); $15 \%$ (B); $20 \%$ (C); 25\% (D); 30\% (E).

\subsection{XRD Analysis}

The XRD patterns of PA/PVA/Ag nanocomposites are shown in Fig. 2. The sharp and intense peaks around $2 \theta$ values of 38, 44 and 64, with 111, 200 and 220 diffraction are related to benign Ag crystalline structure which stabilized by polymeric matrix. A broad peak operating at $2 \theta$ values in the range of $23-28^{\circ}$ is related to the polymeric chains. The XRD patterns inform the presence of silver nanoparticles in nanocomposite forms. The average particle size of PA/PVA/Ag nanocomposite is estimated to be $10-17 \mathrm{~nm}$ for all samples. 


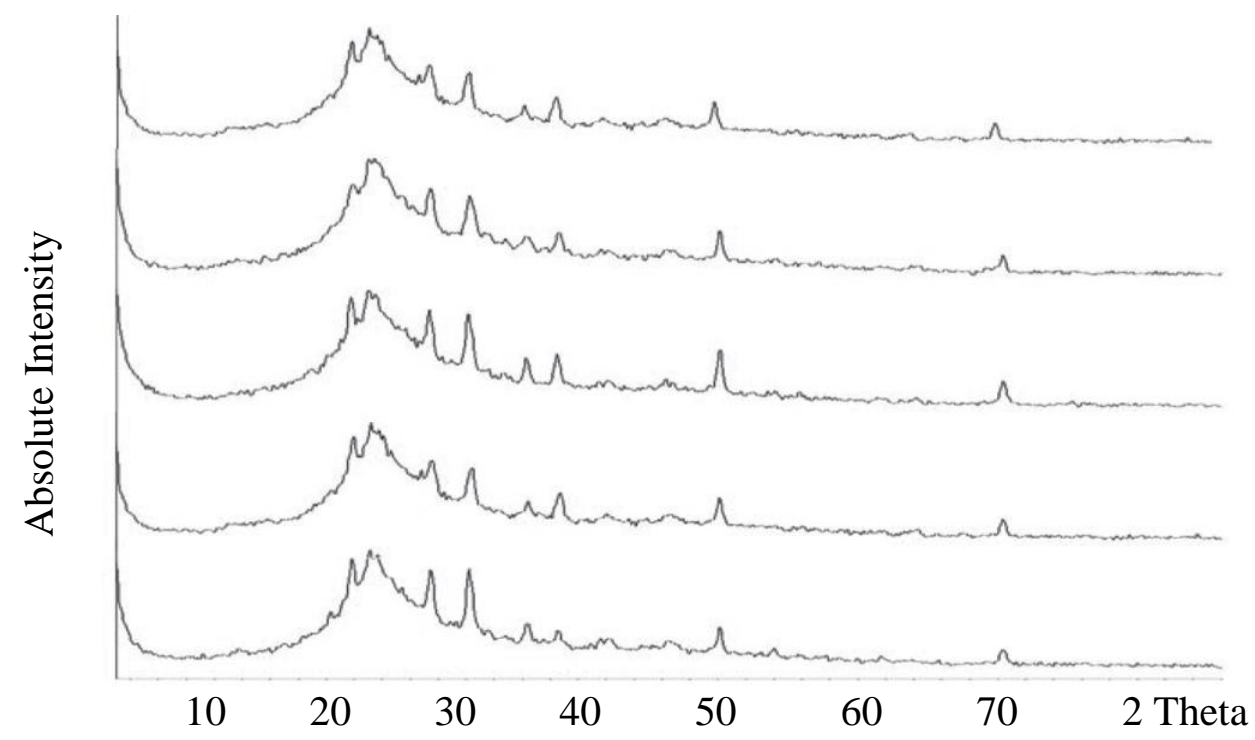

Figure (2) XRD spectra of prepared nanocomposites at different concentrations of silver nanoparticles; $10 \%$ (A); $15 \%$ (B); $20 \%$ (C); $25 \%$ (D); 30\% (E).

\subsection{SEM Analysis}

The SEM was used to collect information regarding morphology and cross-sectional structures of the porous nanocomposite. The images shown in Fig. 3 showed that the nanocomposite formed is porous, have crystalline structure. It is clear that some of nanoparticles are triangular which is a good crystalline structure shape for antibacterial tests [29,30,31].

\subsection{Antibacterial tests of synthesized PA/PVA/Ag nanocomposites}

PA/PVA/Ag nanocomposites were tested for antibacterial activity using Staph. Aureus and E-coli. (Fig. 4) shows the inhibition zones formed by nanocomposite samples. The diameter of the inhibition zones are 8, 9, 14, 10 and $9 \mathrm{~mm}$ and 11, 13, 16, 10 and $9 \mathrm{~mm}$ against E-coli and Staph. Aureus respectively. The results are presented in Table 1. It is shown that $\mathrm{Pa} / \mathrm{PVA}$ composite (Sample of F) used as control matrix, that exhibited no antibacterial activity. The plot of the inhibition zone versus various PA/PVA/Ag nanocomposites is shown in Fig. 4. Referring to Fig. 4. The PA/PVA/Ag nanocomposite (C) with $20 \%$ Ag nanoparticle showed better antibacterial activity against Staph. Auresus and E.coli. Silver exhibits antibacterial property that lead to biomedical applications. 


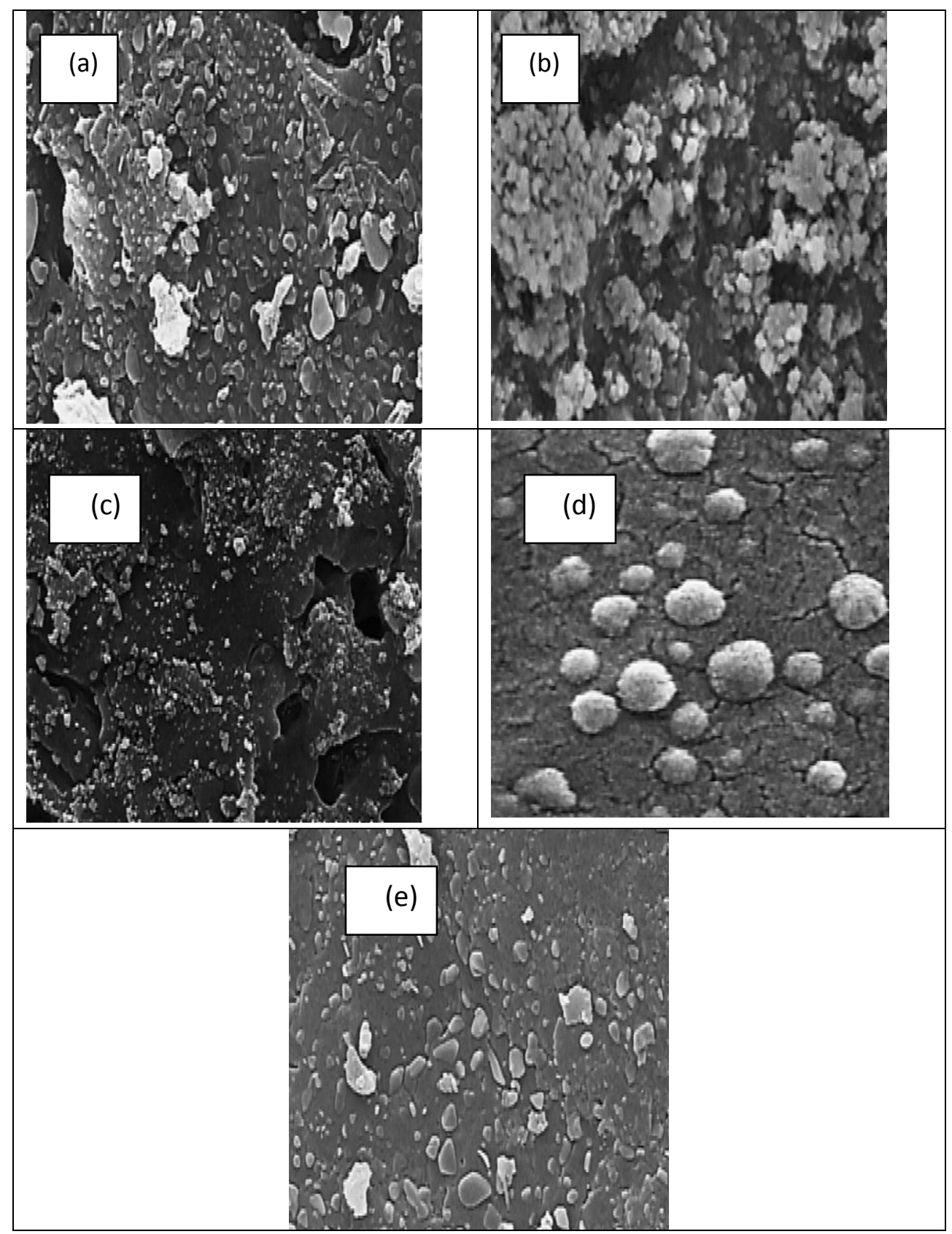

Figure (3) FESEM images of prepared nanocomposites at different concentrations of silver nanoparticles; $10 \%$ (A); $15 \%$ (B); $20 \%$ (C); 25\% (D); 30\% (E)

At low concentrations of nanoparticles, the interaction of particles with wall of the cell of bacteria decreases and at high concentrations of the 
particles, the aggregation of particles increases, hence, the effective surface to volume ratio of particles and the interaction between particles and cell wall of bacteria increase (Fig. 4). Shows the releasing Ag nanoparticles at high, medium and low concentrations of nanoparticles. There are various mechanisms on the action of silver nanoparticles on the bacterial cell [32].
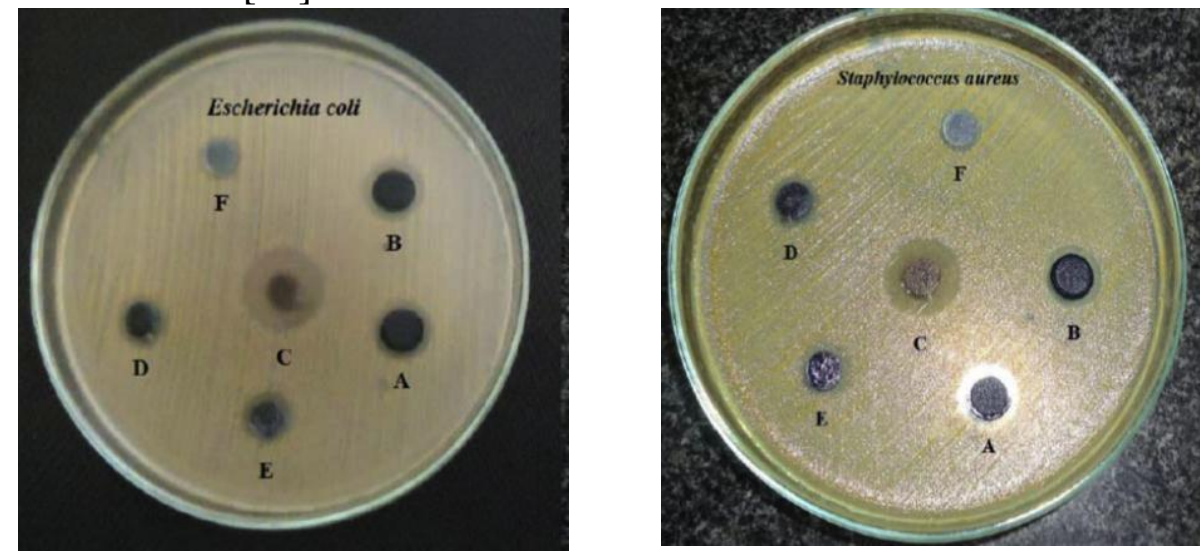

Figure (4) Antibacterial activity of various nanocomposites against two pathogenic strains; E. coli and Staph. aureus by the disk diffusion method; $10 \%$ (A); $15 \%$ (B); 20\% (C); 25\% (D); 30\% (E).

Some of those mechanisms are presented as follows : (i) The formation of free radicals by silver nanoparticles which can be damage the cell membrane and make it porous [33,34]. (ii) The nanoparticles can modulate the signal transduction bacteria that stops the growth of bacteria [35]. (iii) Releasing silver ions by nanoparticles can interact with the thiol groups of many vital enzymes and inactivate them [36,37].

Table 1 Inhibition zones obtained from various nanocomposites at different concentrations of silver nanoparticle; $10 \%$ (A); $15 \%$ (B); $20 \%$ (C); 25\% (D); 30\% (E); 0\% (F) against two pathogenic bacteria.

\section{Samples}

A

B

C

$\mathrm{D}$

E

$\mathrm{F}$
Average of inhibition zones (mm)

\section{E.coli}

8

9

13

10

9

0
Staph. Aureus

11

13

16

10

9

0 


\section{CONCLUSION}

The above study presents the synthesis of PA/PVA/Ag matrix and used for $\mathrm{Ag}$ nanoparticle coating. The synthesized polymers have good efficiency in nanoparticle coating as the particle size was obtained in the range $12-18 \mathrm{~nm}$. This method of low cost, simple. The polymers used Poly Vinyle Alcohol and Poly Aniline are highly biocompatible and biodegradable. The synthesized nanocomposite can be used in different applications, the antibacterial efficiency of the developed nanocomposite was studied since the polymers used eco-friendly materials. The results showed that the synthesized nanocomposite formed have good antibacterial activity.

\section{REFERENCES}

1- Mazor, M. (2004) Electro Chemically Prepared Silver Nano Flakes and Nano Wires. Electro Chem Commun., 6(4):400.

2- Tran, H.V., Tran, LD., Ba, C.T., Vu, H.D., Nguyen, T.N., Pham, D.G and Nguyen, P.X. (2010) Synthesis, Characterization, Antibacterial and Antiproliferative Activities of Monodisperse Chitosan-Based Silver Nanoparticles. Colloid Surf. A: Phesico Chem Eng. Aspects, 360 (1-3):32.

3- Renker, D.H. and Yarin, A.L. (2008) Electro Spinning Jets and Polymer Nano Fibers. Polymer, 49(10): 2387.

4- Liu, Y.L., Chen, W.H. (2009) Preparation and Propertiesof Chitosan/Carbon Nano tube Nano Composite Using Poly (Styrene Sulfonic Acid)- Modified CNTs. Carbohydrate Polymers, 76(1):232-238.

5- Reiad, N.A., Abdel Salam, O.E., Abadir, E.F. (2013) Green Synthesis of Antibacterial Chitosan Films Loaded with Silver Nanoparticles. Chinese Journal of Polyner Science, 31(77):984993.

6- Lee, S.M., Song, K.C., Lee, B.S. (2010). Antibacterial Activity of Silver Nanoparticles Prepared by a Chemical Reduction Method. Korean J. Chem. Eng., 27: 688 - 692. 
7- Khanna, P.K, Singh, N., Gharan, S., Vis Wanath, A.K. (2005) Synthesis of $\mathrm{Ag} /$ Polyaniline Nanocomposite Via an In Situ Photo Redox Mechanism. Mater. Chem. Phys., 92: 214-219.

8- Thomas, V., Rallapu, M.M., Sreedhar, B., Bajpai, S.K.,(2007) A versatile strategy to fabricate hydrogel-silver nanocomposites and investigation of their antimicrobial activity. J. Colloid Interface Sci., 315: 389 - 395.

9- Noritami, H., Igari, N., Kagitani, K., Umezawa, Y., Muratsubaki, Y., Kato. S. (2010) Synthesis and Size Control of Silver Nanoparticle Using Reverse Micelles of Sucrose Fatty Acid Esters. Colloid Polym. Sci., 288: 887 - 891.

10- Tripathy, A, Raichar, A.M., Chandrasekaran, N., Prathna, T.C., Mukherjee, A. (2010) Process Variable in Biomedical of Siver Nanoparticles by Aqueous Extract of Azadiracta in Dica (Neem) Leaves. J. Nano Part. Res., 12: 237 - 246.

11- Ahmad, B.M., Toy, M.Y., Shamli, K., Hussein, M.Z., Lim, J.J. (2011) Green Synthesis and Characterization of Silver/Chitosan/Poly ethylene Glycol Nanocomposites Without any Reducing Agent. Int. J. Mol. Sci., 12: 4872 - 4884.

12- Li, J., Chen, S.H., Zhoo, S.Y., Hou, X.M., Ma, H.Y. and Yang, X.G. (2004) Simple Method for Preparation of Cubic Ag Nano Particles and Their Self-Assembled Films. Thin solid films, 460(1-2):78.

13- Rodrigues, L.B., Leite, H.F., Yoshida, M.I., Saliba, J.B., Junior, A.S.C. and Faraco, A.A.G. (2008) In Vitro Release and Characterization of Chitosan Films as Dexa methasone Carrier. Int. J. Pharm., 368 (1-2): 1.

14- Vimala, K., Murali Mohan, Y., Sambasivudu, K. Navprasad K., Ravindara, S., Narayana, Reddy, N., Padma, Y., Sreedhar, B., and Mohana Rju, K. (2010) Fabrication of Porous Chitosan Films Impregnated with Silver Nano Particles: A Facile Approach for Superior Antibacterial Application. Colloids Surf. B: Biointerfaces, 76(1): 248. 
15- Reiad, N.A. (2017) Using Poly Pyrrole Nano Composites Coated on Rice Husk Ash for The Removal of Anions, Heavy Metals, COD from Textile Wastewater. Housing and Building National Research Center Journal In Press

16- Zhuang, X., Cheng, B., Kang, W. and Xu, X., Carbo. Hydr. Polym. (2009) Antibacterial Activity of Chitosan Tripoly Phosphate Nano Particles Loaded With Silver Nano particles, 75(3): 385.

17- Hwang J.J., Ma, T.W. (2012) Preparation, Morphology and Antibacterial Properties of

Polyacrilonitrile/Montmorillonite/Silver Nanocomposites. Mater. Chem. Phys., 136: 613 - 623.

18- Geo, S., Bilotti, E., Reynolds, C.T., Soykeabkeaw, N., Peijs, T. (2010) Bacterial Cellulose-Poly (Vinyl Alcohol) Nanocomposites Prepared by an In-Situ Process. Mater. Lett., 64: $901-904$.

19- Hebeish, A.A., Abdelhady, M.M., Youssef, A.M. (2012) TiO2 Nano wire and $\mathrm{TiO}_{2}$ Nano wire Doped Ag-PVP Nano composite for Antimicrobial and Self-Cleaning Cotton Textile. Carbonhydr. Polym., 91: 549 - 559 .

20- Barkade, S.S., Naika, J.B., Sanawanels, S.H. (2011) Ultrasound Assisted Mini Emulsion Synthesis of Polyaniline/Ag Nanocomposite and Its Application for Ethanol Vapor Sensing. Colloids Surf., A 378: 94 - 98.

21- Parramezan, M., Eisazadeh, H. (2011) Fabrication and Characterization of Polyaniline Nano composite Modified with Ag Nanoparticles. Compos. Part., B 42: 1980 - 1986.

22- Shyaa, A.A., Hasan, O.A., Abbas, A.M. (2012) Synthesis and Characterization of Poly Aniline/Zeolite Nanocomposite for the Removal of Chromium (VI) from Aqueous Solution. J. Saudi Chem Soc. http:??dx.doi.org/10.1016/J.JJCS.2012.01.001 (In press).

23- Stejscal, J., Quadrat, O., Sapurina, I., Zemek, J., Delinkiewicz, A., Hosik, M., Krivka, I., Proke, J. (2002) Polyaniline Coated Silica Gel, Eur.Polym.J. 38: 631-637. 
24- Fan, H., Wang, H., Yu, X., Zhoo, N., Zhang, X., Xu, J. (2012) Synthesis and Electrochemical Properties of Various Dimensional Polyaniline Micro/Nanostructures: Micro Disks. Nano Spheres and Nano Fibers. Mater. Lett., 71: 70 - 73.

25- Li, Y., Kim, Y., Lee, E., Cai, W., Cho. S. (2006) Synthesis of Silver Nanoparticles Prepared by a Chemical Reduction Method. Korean J. Chem: Eng., 27,688 - 692.

26- Ahmad, B.M., Lim. J.J., Shamili, K., Ibrahim, N.A., Yen Tay, M.Chieng, B.W. (2012) Antibacterial Activity of Silver Bio Nano composites Synthesized by Chemical Reduction Route. Chem. Cont.. J., 6: 101 - 109.

27- Bhadra, J., Sarkar, D. (2010) Size Variation of Polyaniline Nanoparticles Dispersed in Poly Vinyl Alcohol Matrix. Bull. Mater. Sci., 33: 519 - 523.

28- Solomon, S.D., Bahadory, M., Jeyavajasingam, A.V., Rulkowsky, S.A. (2007) Synthesis and Study of Silver Nanoparticles. J. Chem. Educ., 84: 322 - 324.

29- Jones, C.M., Hoek, E.N.V. (2010) A Review of The Antibacterial Effects of Silver Nano Materials and Potential Implications for Human Health, and The Environment. J. Nano Part. Res., 12: $1531-1551$.

30- Ramirez, I.M., Bashir, S., Luo, Z., Lu, J.L. (2009) Green Synthesis and Characterization of Polymer-Stabilized Silver Nanoparticles. Colloids Surf., B73: 187 - 191.

31- Pal., S., Tak, Y.K., Song, J.M. (2007) Does The Antimicrobial Activity of Silver Nanoparticles Depend on The Shape of The Nanoparticle, A Study of The Gram-Negative Bacterium Escherichia Coli. Appl. Environ. Microbiol., 73: 1712 - 1720.

32- Prabhu, S., Poulose, E.K. (2012) Medical Application Silver Nanoparticles: Mechanism of Antimicrobial Action, Synthesis, Medical Applications, and Toxicity Effects. Int. Nano Lett., 2: 110 . 
33- Danilcauk, M., Lund, A., Saldo, J., Yamada, H., Michalik, J. (2006) Conduction Electron Spin Resonance of Small Silver Particles Spectrochim. Acta, Part A 63: 189 - 191.

34- Kim, J.S., Kuk, E., Yu, K., Kim, J.H., Park, S.J.,Lee, H.J., Kim, S.H., Park, Y.K., Park, Y.H., Hwang, C.Y., Kim, Y.K., Lee, Y.S., Jeong, D.H., Cho., M.H. (2007) Antimicrobial Effects of Silver Nanoparticles. Nanomedicine, 3: 95 - 101.

35- Shrivastava, S., Bera, T., Roy, A., Singh, G., Romachandrarao, P., Dash, D. (2007) Characterization of Enhanced Antibacterial Effects of Novel Silver Nanoparticles. Nanotechnology, 18: 1-9.

36- Feng, Q.L., Wu, J., Chen, G.Q., Cui, F.Z. Kim, T.N., Kim, J.O. (2008) A Mechanistic Study of The Antibacterial Effect of Silver Ions on Escherichia coli and Staphyl. Ococcus aureus. J. Biomed. Mater., Res. 52: 662 - 668.

37- Matsumura, Y., Yoshikata, K., Kunisaki, S., Tsuchido, T. (2003) Mode of Bacterial Action of Silver Zeolite and Its Comparison with That of Silver Nitrate. Appl. Environ. Microbiol., 69: 4278 -4281 .

الملخص العربي

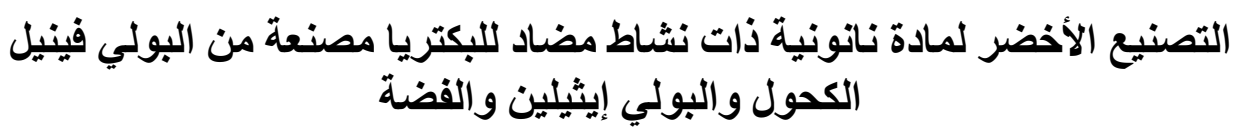

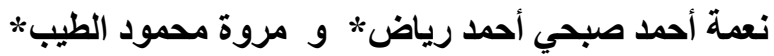

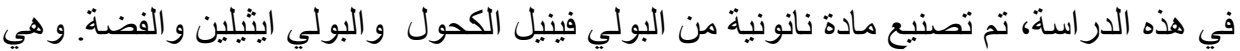

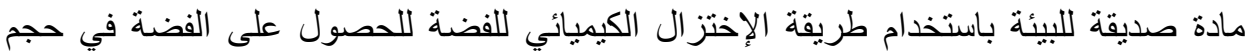

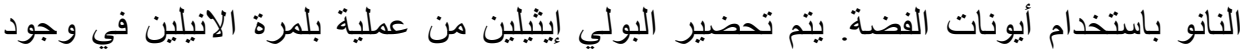

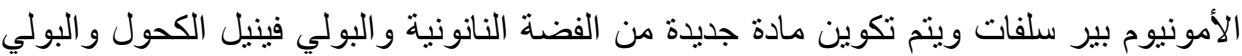

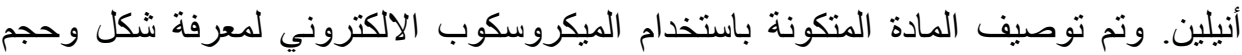

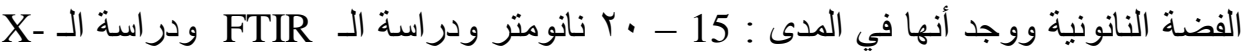

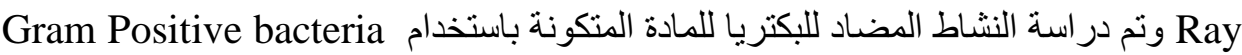
Gram negative bacteria Echerichia coli وباستخدام staphylo coccus aureus Disc ووجد أن المادة المتكونة لها نشاط مضاد للبكتريا وتم اختبار ذلك بواسطة (E.coli) diffusion method

*معه الهندة الصحية والبيئية ـ المركز القومي لبحوث الإسكان والبناء. 